\title{
Physical growth in twins, postmature and small-for-dates children
}

\author{
ROMA CHAMBERLAIN and ALAN DAVEY \\ From the British Births Child Study, Paediatric Unit, St. Mary's Hospital Medical School, London
}

\begin{abstract}
Chamberlain, R., and Davey, A. (1975). Archives of Disease in Childhood, 50, 437. Physical growth in twins, postmature and small-for-dates children. From 16955 livebirths, which occurred throughout the United Kingdom in April 1970 during the British Births Survey, three groups of children (multiple births, postmature, and small-for-dates) were selected together with a $10 \%$ random sample. This report is concerned with the height, weight, and head circumference measurements at 22 months of age. The babies that were heavier at birth showed diminished growth velocity and the small babies catch-up growth. At 22 months the pattern of distribution of weight was much closer to the normal than that of the babies' birthweights. Differences, however, did remain.
\end{abstract}

The experimental evidence that malnutrition in animals during the period of brain cell proliferation can lead to a permanent reduction in the number of brain cells has suggested that malnutrition in human infants might have a permanent effect on their subsequent physical and mental development (Cruise, 1973; Davies and Davis, 1970; Dobbing, 1964; Fitzhardinge and Steven, 1972; Thomson, 1970; Winick, 1969). Prolonged malnutrition is rare during postnatal life among babies in this country, but it may occur prenatally. Damage from fetal malnutrition, if irreversible, could be expected to have a depressive effect on the subsequent development of the child.

The identification of babies who have suffered from fetal malnutrition is not easy. Babies of low birthweight are not a homogeneous group and include many whose weight is within normal limits for their length of gestation. Some babies are genetically small, some have abnormalities or illnesses which affect their growth, while others are retarded due to unfavourable conditions in utero. The social, biological, and medical factors which led to the fetal malnutrition may in some continue to operate and, therefore, have a direct effect after birth on the progress of the child. Despite these considerable limitations, it was felt that there were three groups of babies which were most likely to include substantial numbers who had suffered from fetal

Received 11 November 1974. malnutrition. The first group were the multiple births, because it was assumed that the primary, but not the only, reason for fetal malnutrition might be competition between the fetuses for available nourishment. The second group were the postmature babies, because placental growth is said to cease from the 39th week of pregnancy (Gruenwald, 1963) and thus the likelihood of fetal malnutrition occurring is increased in any baby born after term. The third group were the small-for-dates babies, by virtue of the fact that they showed evidence of fetal retardation at every gestational age.

\section{Plan of investigation}

Method of sampling. During the week beginning 5 April 1970, a detailed survey of all births which occurred in the United Kingdom took place under the auspices of the National Birthday Trust Fund and the Royal College of Obstetricians and Gynaecologists (British Births, 1970). A stratified sample was drawn from this cohort of 16955 livebirths as follows.

(i) A $10 \%$ random sample of all singleton and multiple births.

(ii) All multiple births, i.e. twins and triplets.

(iii) All singleton children who were born at or later than 42 weeks' gestation, whose mothers were recorded as being certain of the date of their last menstrual period and were not recorded as having taken the contraceptive pill for at least 15 months before childbirth.

(iv) All singleton children who were on or below the 5th centile of birthweight for their length of 
gestation, allowing for their sex and maternal parity, but regardless of whether their mother was certain or not of her last normal menstrual period or had taken the contraceptive pill. The children were identified using Tanner and Thomson's (1970) charts for birthweight and length of gestation.

All the children of mothers who stated that they were unmarried, divorced, separated, or widowed at childbirth were then excluded, because of the difficulties involved in tracing and examining them.

The total sample came to 3471 children, of whom 96 were known to have died since birth. Some of the children, of course, belonged to more than one of the above categories. A multiple birth could also be in the random group; a singleton child could be in the random group, in the postmature, or small-for-dates group, or any combination of these.

Examination of children. The surviving children were traced and the examinations arranged by health visitors and other staff of the local health departments. Practically all examinations were carried out by clinic medical officers, a few children were seen by general practitioners and, with the assistance of the Ministry of Defence, the children of members of the armed forces who were living abroad were examined by service doctors. All the health departments in Wales and Northern Ireland took part, but three in England and two in Scotland were unable to do so because of staff shortages; this accounted for nonexamination of $5.4 \%$ of the children. $7 \%$ of the children were not seen because the parents refused or defaulted their appointments, while $11 \cdot 1 \%$ were untraced or were traced too late for inclusion in this first survey at 22 months. A further $2.9 \%$ were in hospital, on holiday, or had left the country. Thus, in all, $73.6 \%$ of the children of the original sample were examined or were known to have died. Table I shows the proportions examined; these did not vary significantly in the three study groups from the random sample.

The results were recorded on a standard form. The first part contained a limited number of questions about the family background: most of this information was already known from the British Births Survey. The second part was a record of a developmental screening test. The third indicated the height, length, weight, and head circumference of the child, together with information on the past medical history and any abnormalities noted on examination. The need for accuracy was stressed and in the majority of instances these measurements were carried out in clinics, a paper tape being provided. The present report relates only to the height, weight, and the head circumference.

Time of examination. Arrangements had been made for the children to be examined between the ages of 94 to 97 weeks (inclusive), but in the event (a power strike having intervened) only about half the total sample were examined during these 4 weeks.

\section{Results}

To ascertain that the random sample was representative it was compared with its British Births Survey equivalent and no statistical difference was found at the $5 \%$ level for any of the following factors: mortality, birthweight, length of gestation, social class, sex, and maternal height, age, parity, and country of birth.

In this report, to standardize for age, only those babies between 94 to 97 weeks old on examination have been included. To test whether this biased the results for each group, they were compared with the remainder of the group and no significant difference was found at the $5 \%$ level for birthweight, sex, maternal age, parity, or height. However, in the random group a few more of those aged 94 to 97 weeks had a known length of gestation, a few less had fathers in the armed forces (due to difficulties in tracing), slightly more of their mothers were born in Northern Ireland (no power strike) and slightly fewer in Wales, Scotland, and India (and Pakistan) than in the remainder of this group. Among the small-for-dates group the mean gestational age of those who were examined at the age of 94 to 97 weeks was slightly shorter; and fewer came from the armed forces and social class II than the rest of this group. There was no difference between those examined and the remainder in the twin and

TABLE I

Number of surviving children in each sample group and proportion examined according to sex of child

\begin{tabular}{|c|c|c|c|c|c|c|c|c|c|}
\hline \multirow{3}{*}{ Sample group ${ }^{\star}$} & \multicolumn{3}{|c|}{ Boys } & \multicolumn{3}{|c|}{ Girls } & \multicolumn{3}{|c|}{ All } \\
\hline & \multirow{2}{*}{ Total } & \multicolumn{2}{|c|}{$\%$ Examined } & \multirow{2}{*}{ Total } & \multicolumn{2}{|c|}{$\%$ Examined } & \multirow[b]{2}{*}{ Total } & \multicolumn{2}{|c|}{$\%$ Examined } \\
\hline & & $\underset{\text { ages }}{\text { All }}$ & $94-97 \mathrm{w}$ & & $\begin{array}{c}\text { All } \\
\text { ages }\end{array}$ & 94-97 w & & $\begin{array}{c}\text { All } \\
\text { ages }\end{array}$ & 94-97 w \\
\hline $\begin{array}{l}\text { Random } \\
\text { Twins } \\
\text { Postmature } \\
\text { Small-for-dates }\end{array}$ & $\begin{array}{l}828 \\
163 \\
495 \\
442\end{array}$ & $\begin{array}{l}72 \cdot 3 \\
72 \cdot 4 \\
78 \cdot 4 \\
72 \cdot 2\end{array}$ & $\begin{array}{l}51 \cdot 7 \\
48 \cdot 5 \\
57 \cdot 4 \\
53 \cdot 6\end{array}$ & $\begin{array}{l}751 \\
146 \\
477 \\
357\end{array}$ & $\begin{array}{l}70 \cdot 0 \\
70 \cdot 9 \\
74 \cdot 6 \\
69 \cdot 5\end{array}$ & $\begin{array}{l}50 \cdot 2 \\
53 \cdot 4 \\
59 \cdot 1 \\
52 \cdot 9\end{array}$ & $\begin{array}{r}1579 \\
309 \\
972 \\
799\end{array}$ & $\begin{array}{l}71 \cdot 2 \\
73 \cdot 8 \\
76 \cdot 5 \\
71 \cdot 0\end{array}$ & $\begin{array}{l}51 \cdot 0 \\
50 \cdot 8 \\
58 \cdot 2 \\
53 \cdot 3\end{array}$ \\
\hline
\end{tabular}

$\star$ These groups are not mutually exclusive and relate to 1771 boys and 1604 girls. 
postmature groups. These differences, however, are very small and are unlikely to affect any of the results given here.

Examiners were asked to record any difficulties encountered in the measurements of weight, height, length, and head circumference, e.g. use of bathroom scales, lack of co-operation from the child, unusual head shapes or hair styles. Only those with no reported difficulties have been included in this analysis.

The results were tested to see whether the three groups, postmature, twins, and small-for-dates babies differed from the random sample. For this a two-sample ' $t$ ' test was applied to the difference between each group and the random sample for boys and girls separately. For each comparison this yielded two ' $t$ ' values which were approximately standard normal deviates, as the degrees of freedom were large. These two were then pooled to give a one test statistic for each group compared with the random sample. To test the differences between boys and girls, four ' $t$ ' test values were obtained by comparing the sexes within each of the four groups. These four standard normal deviates were then pooled to give a single test statistic.

Random sample. There were 1579 children alive at 2 years of age in the random sample, 805 (51\%) were examined between the age of 94 to 97 weeks (Table I). The number of children and the mean physical measurements of those where there were no difficulties in measuring are shown in Table II. As can be seen, the boys were significantly heavier, taller, and had larger head circum- ference measurements than the girls for all comparisons $(P<0.001)$.

Both height and length measurements of the children had been requested, though the two measures are naturally highly correlated (e.g. for males in this sample $\mathbf{r}=0.83$ ). On average the lengths were slightly greater than the heights. Using the technique described by Pitman (1939), the variance of the length was found to be greater than that of the height $(P<0.01)$, so that the measurements of length appeared, therefore, to be less reliable as an indicator of skeletal size. In addition, height was recorded more often than length (Table II), so that it seemed to be a preferable measurement for this analysis.

Correlation matrices were constructed for the male random group for weight, birthweight, height, and head circumference. As might be expected, all the variables were correlated ( $P<0.001$ for each).

Multiple births. There were 309 babies, all twins, known to be alive by the age of 2 years, of whom $157(50 \cdot 8 \%)$ were examined between the ages of 94 to 97 weeks.

At birth the mean weight of the twins was much smaller than that of the random group $(P<0 \cdot 001)$ but by 94 to 97 weeks they were just significantly lighter than the random group $(P<0.05)$ (Table II). However, analysis of covariance of weight against birthweight showed the twins to be heavier than the random group after allowing for their birthweight, so that they had put on relatively much more weight. The growth of infants is quicker prenatally than postnatally and the rate decreases as the baby

TABLE II

Mean physical measurements of boys and girls at 94 to 97 weeks of age, excluding those with difficulties in measuring

\begin{tabular}{|c|c|c|c|c|c|c|c|c|c|c|c|c|}
\hline \multirow{2}{*}{ Measurements } & \multicolumn{3}{|c|}{ Random } & \multicolumn{3}{|c|}{ Twins } & \multicolumn{3}{|c|}{ Postmature } & \multicolumn{3}{|c|}{ 'Small' } \\
\hline & No. & Mean & $\mathrm{SD}$ & No. & Mean & SD & No. & Mean & SD & No. & Mean & SD \\
\hline \multicolumn{13}{|l|}{$\begin{array}{l}\text { Boys } \\
\text { At Birth }\end{array}$} \\
\hline $\begin{array}{l}\text { Birthweight (g) } \\
\text { At } 94-97 \text { weeks }\end{array}$ & 428 & 3384 & 520 & 79 & 2680 & 529 & 283 & 3524 & 488 & 237 & 2431 & 324 \\
\hline $\begin{array}{l}\text { Weight }(\mathbf{k g}) \\
\text { Height }(\mathrm{cm}) \\
\text { Length }(\mathrm{cm}) \\
\text { Head size }(\mathrm{cm})\end{array}$ & $\begin{array}{l}348 \\
373 \\
314 \\
375\end{array}$ & $\begin{array}{l}12 \cdot 45 \\
84 \cdot 4 \\
85 \cdot 0 \\
49 \cdot 6\end{array}$ & $\begin{array}{l}1 \cdot 50 \\
4 \cdot 0 \\
4 \cdot 1 \\
1 \cdot 5\end{array}$ & $\begin{array}{l}71 \\
61 \\
56 \\
70\end{array}$ & $\begin{array}{l}12 \cdot 28 \\
83 \cdot 6 \\
83 \cdot 8 \\
49 \cdot 4\end{array}$ & $\begin{array}{l}1 \cdot 44 \\
4 \cdot 0 \\
4 \cdot 1 \\
1 \cdot 5\end{array}$ & $\begin{array}{l}222 \\
247 \\
215 \\
260\end{array}$ & $\begin{array}{l}12 \cdot 17 \\
84 \cdot 3 \\
85 \cdot 2 \\
49 \cdot 5\end{array}$ & $\begin{array}{l}1 \cdot 58 \\
3 \cdot 6 \\
4 \cdot 2 \\
1 \cdot 5\end{array}$ & $\begin{array}{l}197 \\
197 \\
179 \\
209\end{array}$ & $\begin{array}{l}11 \cdot 52 \\
82 \cdot 3 \\
82 \cdot 8 \\
48 \cdot 6\end{array}$ & $\begin{array}{l}1 \cdot 35 \\
3 \cdot 5 \\
3 \cdot 7 \\
1 \cdot 6\end{array}$ \\
\hline $\begin{array}{l}\text { Girls } \\
\text { At birth }\end{array}$ & & & & & & & & & & & & \\
\hline $\begin{array}{l}\text { Birthweight (g) } \\
\text { At } 94-97 \text { weeks }\end{array}$ & 377 & 3267 & 535 & 78 & 2430 & 456 & 281 & 3432 & 483 & 189 & 2351 & 306 \\
\hline $\begin{array}{l}\text { Weight }(\mathbf{k g}) \\
\text { Height }(\mathrm{cm}) \\
\text { Length }(\mathrm{cm}) \\
\text { Head size }(\mathrm{cm})\end{array}$ & $\begin{array}{l}313 \\
327 \\
274 \\
329\end{array}$ & $\begin{array}{l}11 \cdot 69 \\
82 \cdot 7 \\
83 \cdot 5 \\
48 \cdot 3\end{array}$ & $\begin{array}{l}1 \cdot 47 \\
3 \cdot 9 \\
3 \cdot 9 \\
1 \cdot 5\end{array}$ & $\begin{array}{l}66 \\
67 \\
56 \\
75\end{array}$ & $\begin{array}{l}11 \cdot 34 \\
81 \cdot 8 \\
83 \cdot 2 \\
48 \cdot 1\end{array}$ & $\begin{array}{l}1 \cdot 22 \\
3 \cdot 5 \\
3 \cdot 8 \\
1 \cdot 5\end{array}$ & $\begin{array}{l}236 \\
248 \\
215 \\
245\end{array}$ & $\begin{array}{l}11 \cdot 66 \\
83 \cdot 0 \\
83 \cdot 7 \\
48 \cdot 3\end{array}$ & $\begin{array}{l}1 \cdot 36 \\
4 \cdot 1 \\
4 \cdot 5 \\
1 \cdot 6\end{array}$ & $\begin{array}{l}146 \\
163 \\
134 \\
158\end{array}$ & $\begin{array}{l}10 \cdot 58 \\
80 \cdot 2 \\
80 \cdot 5 \\
47 \cdot 3\end{array}$ & $\begin{array}{l}1 \cdot 32 \\
3 \cdot 9 \\
3 \cdot 7 \\
1 \cdot 5\end{array}$ \\
\hline
\end{tabular}


gets older, so that if this pattern is uninterrupted by birth then it would be expected that prematurelyborn babies would show a greater increase than those born postmaturely. The twins had a shorter mean length of gestation than the random sample which could account for part or all of the extra weight increase after birth.

The lengths of the babies were not recorded at birth so that the distribution could not be compared in the same way as the weight and birthweight. However, the differences in the degree of significance between the twins and the random group for mean height was similar to that for weight, the twins being slightly shorter than the random group $(P<0.05)$.

In an analysis of covariance the relation of weight against height was studied. No significant difference was found between the mean weight of the random and twin groups after allowance had been

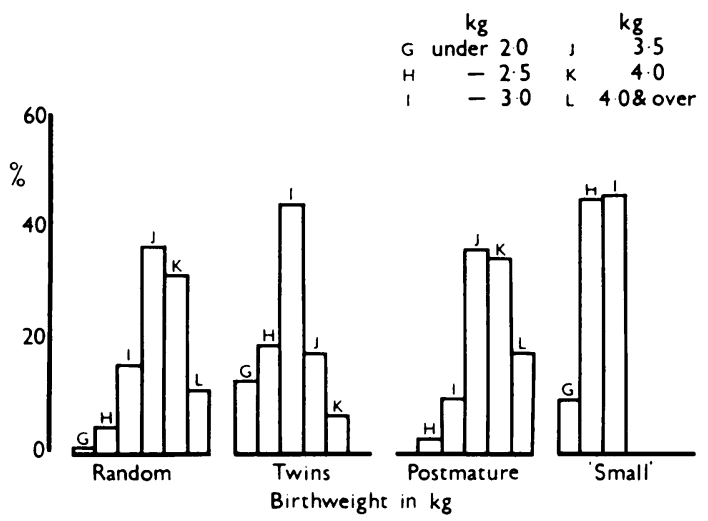

(a)

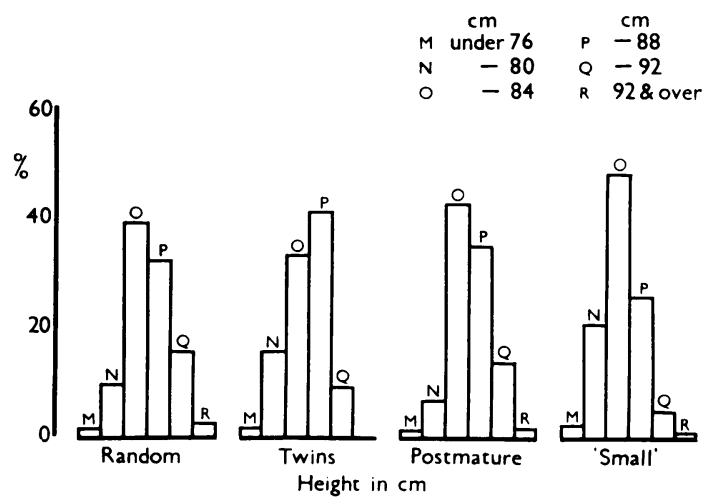

(c) made for height. Thus the twins had the same 'build' as the random group at 22 months though they were lighter and shorter. On the other hand their mean head circumference showed no difference at the $5 \%$ level from the random group. Therefore, unless the twins at birth had abnormally large heads for their birthweight, it can be assumed that at the time when maximum head growth rate had passed, the twins had caught up with the random group. This is illustrated in the Fig.

Postmature babies. There were 972 babies known to be alive at the time of the study, 286 $(58 \cdot 2 \%)$ of whom were examined between the ages of 94 to 97 weeks.

The average birthweight of the postmature babies was higher $(P<0 \cdot 001)$, but by 94 to 97 weeks their mean measurements for height, weight, and head circumference did not vary from those of

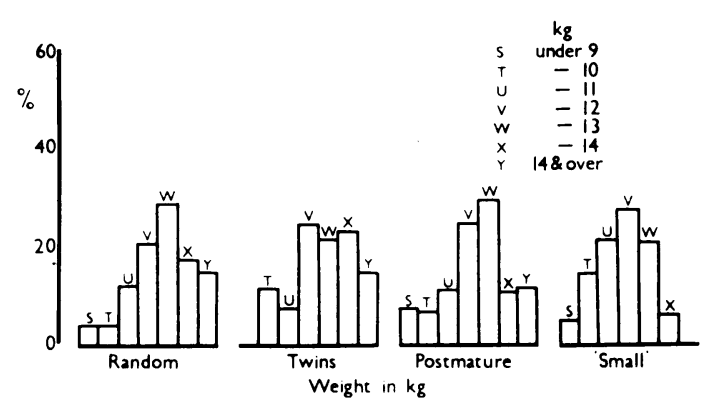

(b)
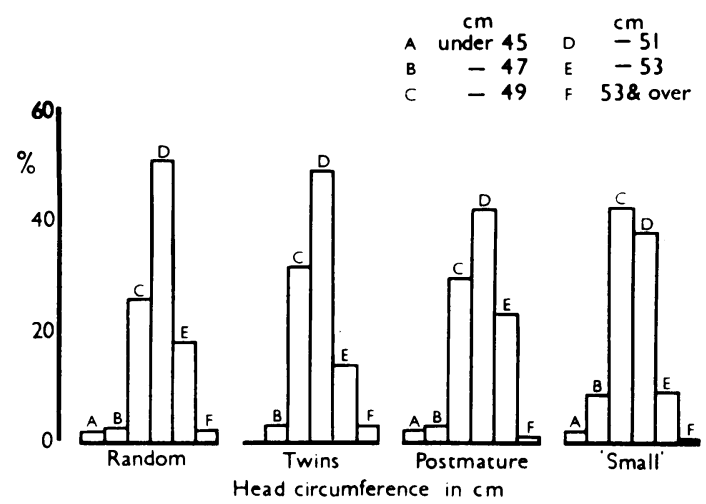

(d)

FIG.-Boys from the four groups. (a) Distribution of weight at birth; (b) distribution of weight at 94-97 weeks; (c) distribution of height at 94-97 weeks; (d) distribution of head circumference at 94-97 weeks. 
the random group. The postmature children were, however, on average slightly lighter for their height $(P<0.05)$, and they had put on relatively less weight after allowing for their birthweight than the random group, but this may be accounted for by their longer length of gestation, and further study is being made of this. As can be seen in the Fig., the distribution for all the measurements of the postmature babies came much closer to that of the random group.

Small-for-dates babies. There were 799 children, 442 boys and 357 girls, alive at the time of the survey, of whom $426(53 \cdot 3 \%)$ were examined at the age of 94 to 97 weeks. The sample was picked using Tanner and Thomson's charts (1970) which are based on the single, legitimate, live, and stillbirths occurring in Aberdeen from 1948 to 1964 with different centile systems for boys and girls, and for first- and later-born children. As our sample was selected from one week's births occurring nationally in the early part of the year, the constitution of the sample is slightly different, there being more boys born during the week who fulfilled the criteria for selection. Throughout the paper the measurements for boys and girls have been analysed separately.

The mean birthweight of the small-for-dates babies was obviously much lower than that of the random group $(P<0.001)$, and closely resembled that of the twins; by the age of 94 to 97 weeks their mean weights were still much less than those of the random sample $(P<0.001)$. After allowing for birthweight, there was no overall evidence that they had put on more weight than the random group, but nevertheless, as can be seen in the Fig., some of the children had increased their weight rapidly compared with others so that the distribution tended towards normal.

These children were shorter than the random sample $(P<0.001)$ and analysis of covariance showed that they were on average much lighter for their height $(P<0 \cdot 001)$. They also had smaller mean head sizes $(P<0.001)$, but the Fig. shows that, like weight and height, the head size of some of the children had increased rapidly, tending to produce a distribution resembling that of the random sample.

A correlation matrix was constructed for the male small-for-dates group for weight, height, head circumference, and birthweight. Like the random group, the first three are intercorrelated $(P<0 \cdot 001)$, but birthweight correlated only with height $(P<0.01)$.

Since the distribution of the weight of the small- for-dates babies was tending towards the normal, it would suggest that the majority of factors which caused the depression of their birthweight were no longer functioning or were being compensated for postnatally. However, by definition the distribution of the birthweight for the small-for-dates babies is curtailed and this must inhibit correlation between birthweight and the measurements at a later date.

\section{Discussion}

This paper is the first report of a study of the subsequent physical and mental progress of three groups of babies who might have been malnourished during fetal life. The children were selected from a national cohort of one week's births and have been compared with a $10 \%$ random sample as a control.

The results presented are those concerned with the physical development of the children at 22 months of age when their height and weight were still rapidly increasing but their maximum period of head growth had passed, and differences in the three groups have been established. At 22 months both the twins and the small-for-dates babies were on average lighter and shorter than the sample population but, whereas the twins were of the same build, the small-for-dates babies were much lighter for their heights. The head circumference measurements of the twins showed no overall difference from the random sample, though those of the small-for-dates babies were smaller. Thus, while the head size of the latter was in the same proportion to their body size as the sample population, the twins had comparatively larger heads for their bodies. The mean measurements of the postmature group did not vary statistically from the control group, but they were lighter than expected for their height.

The Ounsteds (1973) analysed the postnatal growth of a sample of small-for-dates and largefor-dates babies which they defined as those more than 2 SD from the mean (i.e. roughly below the 3rd and above the 97th centile). They showed the tendency for their height, weight, and head circumference measurements to revert towards the mean. This series has confirmed these findings in the small-for-dates children at 22 months of age, and has shown that the weights of twins and postmature children also have a pattern of distribution much closer to that of the random than that of their birthweights.

Thus the velocity of growth of smaller babies has been shown to be more rapid than that of the heavier children, so that while the lighter ones appear to be catching up, the heavier babies show evidence of 
holding back. Any conclusions, therefore, concerning the finding of a simple association or lack of it between the physical and mental progress of these groups of children must take into account the diversity of postnatal growth patterns. These measurements will be analysed in greater detail taking into account the length of gestation, the centile distribution in the various groups, and the effect of the social, biological, maternal, and neonatal factors about which we have information.

A number of medical officers undertaking the examinations noted that they were unable to identify easily the group to which the children belonged, despite the differences which have been described. But for each there is a wide range of observations resulting in a considerable overlap between the groups as shown in the Fig. The small-for-dates boys, for example, all weighed less than $3000 \mathrm{~g}$ at birth, but by the time they were 94 to 97 weeks of age $4 \%$ weighed less than $9 \mathrm{~kg}$ and $5 \%$ weighed over $14 \mathrm{~kg}$. On the other hand, $88 \%$ of the postmature boys weighed over $3000 \mathrm{~g}$ at birth and by 94 to 97 weeks $7 \%$ weighed less than $9 \mathrm{~kg}$ and $11 \%$ over $14 \mathrm{~kg}$. Thus, the old paediatric adage that small babies catch up with others by the age of 2 years in practice appears to be true; for the small residual deficiencies would not be appreciable immediately to anyone examining the children.

The fear that a fat baby becomes a fat child who becomes a fat adult has led to the increasing practice in child health clinics of monitoring the weight gain of babies using centile charts, and rapid changes from lower ratings to higher ones are sometimes taken to indicate the need for dietary control. These findings emphasize how cautious such conclusions should be.
We thank the many people who helped us to undertake this survey; Professor J. C. Waterlow for suggesting the survey; the Medical Research Council for providing funds; the National Birthday Trust Fund for use of British Births Survey data; St. Mary's Hospital Medical School and particularly Professor T. E. Oppé for help; Oxford Regional Hospital Board for putting data onto punch cards; Mrs. Doreen Irving and the Department of Medical Statistics at the London School of Hygiene and Tropical Medicine for transferring data to tape and editing it; Professor B. Benjamin of City University for advice; and finally all clinic medical officers, general practitioners, and service doctors who undertook examinations, and local health authority administrative staff and health visitors who traced and found the children.

\section{REFERENCES}

Chamberlain, R., Chamberlain, G., Howlett, B., and Claireaux, A. (1975). British Births 1970, Vol. I, First Week of Life. Heinemann Medical Books, London. (In the press.)

Cruise, M. O. (1973). A longitudinal study of the growth of low birth weight infants. I. Velocity and distance growth, birth to 3 years. Pediatrics, 51, 620.

Davies, P. A., and Davis, J. P. (1970). Very low birth-weight and subsequent head growth. Lancet, 2, 1216.

Dobbing, J. (1964). The influence of early nutrition on the development and myelination of the brain. Proceedings of the Royal Society (Biol.), 159, 503.

Fitzhardinge, P. M., and Steven, E. M. (1972). The small-for-date infant. I. Later growth patterns. Pediatrics, 49, 671 .

Gruenwald, P. (1963). Chronic fetal distress and placental insufficiency. Biologia Neonatorum, 5, 215.

Ounsted, M., and Ounsted, C. (1973). On fetal growth rate Clinics in Developmental Medicine No. 46. Spastics International Medical Publications, Heinemann Medical Books, London.

Pitman, E. J. G. (1939). A note on normal correlation. Biometrika, 31, 9.

Tanner, J. M., and Thomson, A. M. (1970). Standards for birthweight at gestation periods from 32 to 42 weeks, allowing for maternal height and weight. Archives of Disease in Childhood, 45, 566.

Thomson, A. M. (1970). The evaluation of human growth patterns. American Fournal of Diseases of Children, 120, 398.

Winick, M. (1969). Malnutrition and brain development. Fournal of Pediatrics :74, 667.

Correspondence to Dr. R. Chamberlain, Paediatric Unit, St. Mary's Hospital Medical School, London W2. 